\title{
Revisiting the dangers of the coronavirus in the ophthalmology practice
}

\author{
Ivan Seah $\mathbb{1}^{1} \cdot$ Xinyi Su ${ }^{1,2,3} \cdot$ Gopal Lingam $\mathbb{B}^{1,3}$
}

Received: 25 January 2020 / Accepted: 27 January 2020 / Published online: 6 February 2020

(c) The Author(s) 2020. This article is published with open access

\section{Introduction}

Every year, during the Lunar New Year, the largest human migration in the world occurs in China. Almost 3 billion passenger-journeys are made as travellers reunite with distant families [1]. This year, things are different. The recent emergence of a novel coronavirus (2019-nCoV), which caused an outbreak of viral pneumonia in Wuhan, China, has led to three Chinese cities; Wuhan, Huanggang, Ezhou, placed under lockdown to curb transmission. The 2019nCoV has sparked global concern regarding the likelihood of the epidemic turning out like the 2003 Severe Acute Respiratory Syndrome Coronavirus (SARS-CoV), where more than 8000 people were infected with 774 mortalities [2]. Healthcare workers represented $20 \%$ of the infected [2]. The 2019-nCoV serves as a reminder of the potential dangers posed by coronaviruses to both patients and doctors alike.

\section{Coronaviruses: what are they?}

Coronaviruses $(\mathrm{CoV})$ belong to the subfamily Coronavirinae, in the family Coronaviridae of the order Nidovirales. There are four genera: Alphacoronavirus, Betacoronavirus, Gammacoronavirus and Deltacoronavirus [3]. It is a single positive-sense RNA virus. Mutation rates of RNA viruses

$\triangle$ Ivan Seah

ivan.seah@mohh.com.sg

1 Department of Ophthalmology, National University Hospital, Singapore, Singapore

2 Institute of Molecular and Cell Biology (IMCB), Agency for Science, Technology and Research (A*STAR),

Singapore, Singapore

3 Department of Ophthalmology, Yong Loo Lin School of Medicine, National University Singapore, Singapore, Singapore are greater than DNA viruses, suggesting a more efficient adaptation process for survival. The genome codes for at least four main structural proteins: spike (S), membrane $(\mathrm{M})$, envelope (E), nucleocapsid $(\mathrm{N})$ proteins and other accessory proteins which aid the replicative processes and facilitate entry into cells [4]. Figure 1 summarises the coronavirus's structure and the function of the structural proteins. CoVs mainly affect birds and mammals. Prior to 2019, there were only six CoVs that can infect human and cause respiratory diseases: $\mathrm{HCoV}-229 \mathrm{E}, \mathrm{HCoV}-\mathrm{OC} 43$, HCoV-NL63, HKU1, SARS-CoV, MERS-CoV. The last 2 are capable of causing severe respiratory syndrome in humans.

\section{The Wuhan Novel Coronavirus (2019-nCoV)}

On the 31st of December 2019, the World Health Organisation (WHO) was alerted by Chinese authorities of a series of pneumonia-like cases in the city of Wuhan, a city the size of London with about 11 million people. It was quickly identified that the first human infections likely originated from Huanan Seafood Market in Wuhan [5]. Two weeks later, a group of Chinese scientists, along with WHO announced that a new coronavirus (2019-nCoV), identified through genomic sequencing, was the culprit of the pneumonia [6]. Symptoms of infection included fever, malaise, dry cough, shortness of breath and respiratory distress.

While such an effort is a crucial response to tackling the crisis, understanding of the virus's transmission patterns still remain murky. Initially thought to be a virus with mainly animal-human transmission, this was proven to be untrue when the number of cases surged over the weekend of 18th and 19th January and reports of healthcare workers being infected surfaced [7]. As of the 23rd of January 2020, 622 have been infected globally with 17 mortalities all located within China.

A timeline of key events up till the 23rd of January is represented in Fig. 2. 


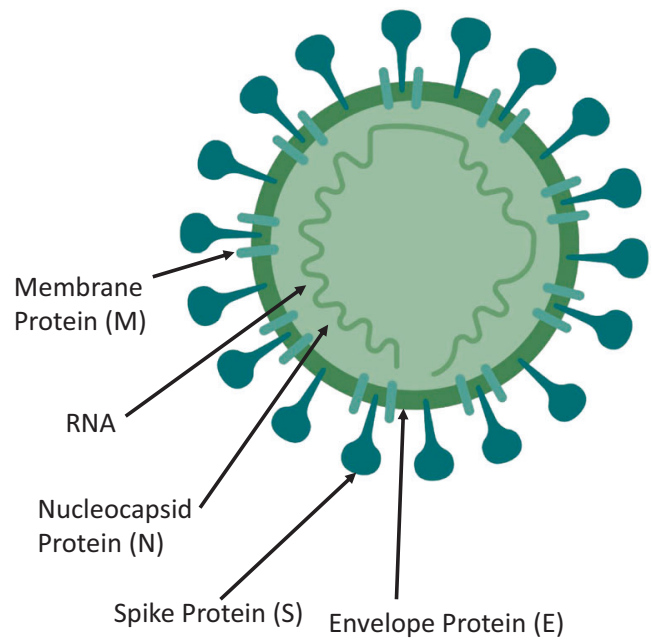

\begin{tabular}{|c|c|}
\hline Structural Protein & Function of Protein \\
\hline Nucleocapsid Protein (N) & $\begin{array}{l}\text { Bound to RNA genome } \\
\text { to make up nucleocapsid }\end{array}$ \\
\hline Spike Protein (S) & $\begin{array}{l}\text { Critical for binding of } \\
\text { host cell receptors to } \\
\text { facilitate entry of host } \\
\text { cell }\end{array}$ \\
\hline Envelope Protein (E) & $\begin{array}{l}\text { - Interacts with } \mathrm{M} \text { to form } \\
\text { viral envelope }\end{array}$ \\
\hline Membrane Protein (M) & $\begin{array}{l}\text { - Central organiser of CoV } \\
\text { assembly } \\
\text { - Determines shape of } \\
\text { viral envelope }\end{array}$ \\
\hline
\end{tabular}

Fig. 1 Main structure of coronaviruses.

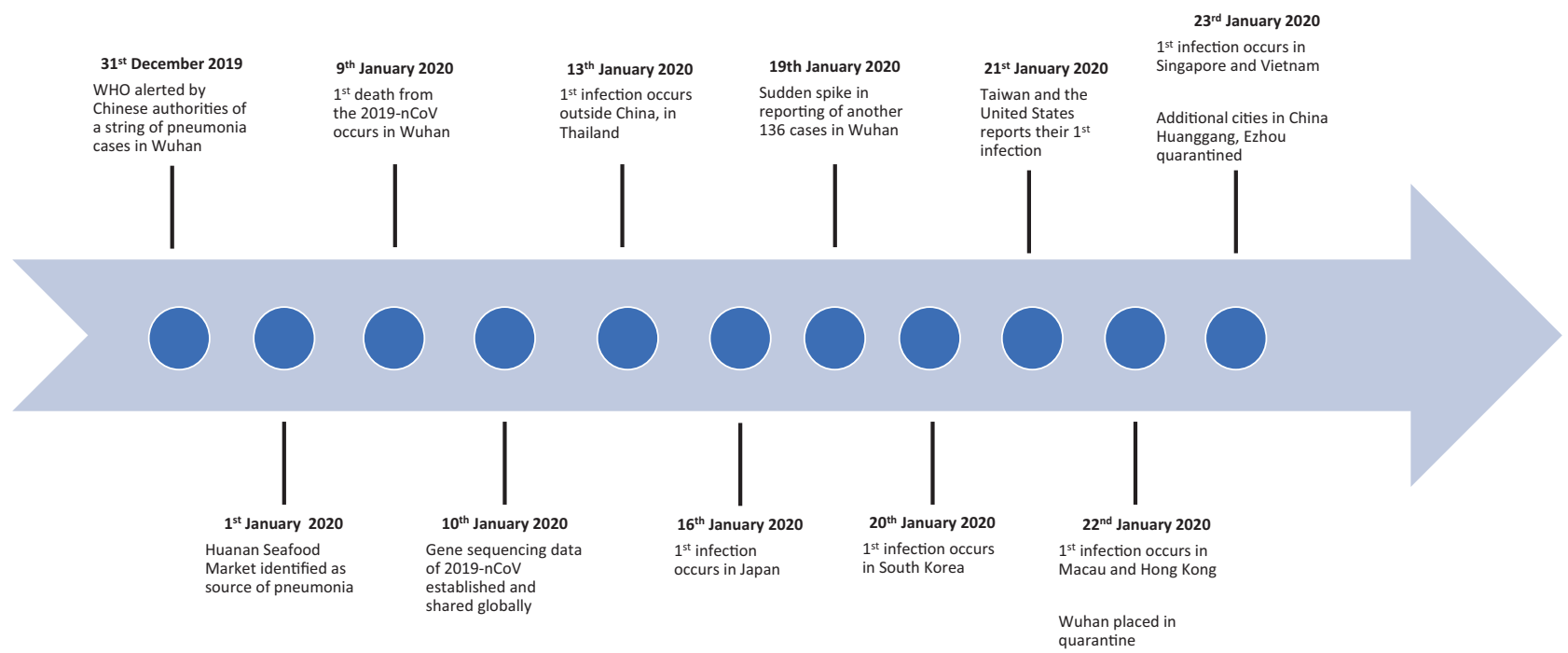

Fig. 2 Key events in the 2019-nCoV outbreak.

\section{A possible threat in the ophthalmology clinic}

While the 2019-nCoV transmission route is still unknown, countries have been preparing measures based on past experiences with coronaviruses namely SARS-CoV and MERS-CoV. These viruses transmit primarily through droplets and other bodily secretions. In the ophthalmology practice, healthcare workers may be particularly susceptible to these infections.

Firstly, ophthalmologists are extremely reliant on physical examination during patient consultation. Of particular concern is the proximity between the patient and ophthalmologist during the slit lamp microscope examination. It has been shown that droplets from a cough or sneeze can be propelled for up to $6 \mathrm{~m}$ [8], a range that definitely encompasses the distance between the patient and ophthalmologist.

Secondly, during the SARS-CoV epidemic, clinical reports have suggested tears as a medium of infection. In a case series by Loon et al., it was shown that viral RNA of the SARS-CoV can be detected by reverse-transcription polymerase chain reaction (RT-PCR) from the tears of infected individuals [9]. While anecdotal in nature, such accounts highlight the possible infectivity of tears, a fluid which ophthalmologists and instruments come in contact on a daily basis. If true, this represents a crucial need for further development of disinfection and personal protective equipment (PPE) protocols for the ophthalmology clinic. 


\section{Bringing back strategies to prevent transmission}

In view of the potential threat in the ophthalmology practice, it may be prudent to revisit the strategies that successfully curbed the transmission of SARS in 2003 [10]. With particular relevance to the ophthalmic practice, it may be beneficial to triage patients according to produced surveillance case definitions [11]. In 2003, the WHO launched a case classification scheme which triaged patients into general, suspect and probable categories. Ophthalmology practices in Hongkong, a country badly hit by SARS, recommended the full PPE for all cases regardless of SARS status. For suspect and probable cases, appointments were recommended to be deferred unless in the event of an ophthalmic emergency. These patients were seen in an isolation ward. An emphasis on hand hygiene measures and stocking up of PPE such as N95 masks, gloves, gowns and googles should also be considered while the mode of transmission is being identified. Decontamination and sterilisation protocols of clinical rooms and equipment should also be improved on as coronaviruses have been found to survive in environments outside the body for a long time [12]. For instance, it is still not established if higher concentrations of dilute bleach (1:10), a chemical used to sterilise the Goldmann applanation tonometer, can be utilised to eliminate coronaviruses [13]. Other shared equipment like the B-scan probe and contact lenses for photocoagulation will also need strict sterilisation protocols. Finally, the reduction of non-urgent ophthalmic operations should also be considered as the risk of viral transmission may outweigh the surgical benefits. For emergency operations, full PPE can be considered to reduce the probability of healthcare transmission.

As the WHO Director-General, Tedros Adhanom Ghebreyesus highlighted, "Make no mistake: this is an emergency in China. But it has not yet become a global health emergency. It may yet become one." It is currently very difficult to predict the eventual impact of the 2019-nCoV. However, it will be prudent to utilise the lessons gained from SARS-CoV and prepare for the worst. Until a vaccine is created, public health strategies are likely the best weapons against the enemy.

\section{Compliance with ethical standards}

Conflict of interest The authors declare that they have no conflict of interest.
Publisher's note Springer Nature remains neutral with regard to jurisdictional claims in published maps and institutional affiliations.

Open Access This article is licensed under a Creative Commons Attribution 4.0 International License, which permits use, sharing, adaptation, distribution and reproduction in any medium or format, as long as you give appropriate credit to the original author(s) and the source, provide a link to the Creative Commons license, and indicate if changes were made. The images or other third party material in this article are included in the article's Creative Commons license, unless indicated otherwise in a credit line to the material. If material is not included in the article's Creative Commons license and your intended use is not permitted by statutory regulation or exceeds the permitted use, you will need to obtain permission directly from the copyright holder. To view a copy of this license, visit http://creativecommons. org/licenses/by/4.0/.

\section{References}

1. Bloomberg News. China will rack up three billion trips during world's biggest human migration. Bloomberg News; January 2020.

2. WHO. Summary table of SARS cases by country, 1 November 2002-7 August 2003. World Health Organisation (WHO); 2003.

3. Chen Y, Liu Q, Guo D. Coronaviruses: genome structure, replication, and pathogenesis. J Med Virol. [e-pub ahead].

4. Schoeman D, Fielding BC. Coronavirus envelope protein: current knowledge. Virol J 2019;16:69.

5. WHO. Pneumonia of unknown cause-China. 2020. https://www. who.int/csr/don/05-january-2020-pneumonia-of-unkown-causechina/en/.

6. Hui DS, E IA, Madani TA, Ntoumi F, Kock R, Dar O, et al. The continuing 2019-nCoV epidemic threat of novel coronaviruses to global health-the latest 2019 novel coronavirus outbreak in Wuhan, China. Int J Infect Dis 2020;91:264-6.

7. Javier C, Hernández AR. China confirms new coronavirus spreads from humans to humans. America: The New York Times; 2020.

8. Xie X, Li Y, Chwang AT, Ho PL, Seto WH. How far droplets can move in indoor environments-revisiting the Wells evaporationfalling curve. Indoor Air. 2007;17:211-25.

9. Loon S-C, Teoh SCB, Oon LLE, Se-Thoe S-Y, Ling A-E, Leo Y-S, et al. The severe acute respiratory syndrome coronavirus in tears. Br J Ophthalmol. 2004;88:861-3.

10. Chan WM, Liu DT, Chan PK, Chong KK, Yuen KS, Chiu TY, et al. Precautions in ophthalmic practice in a hospital with a major acute SARS outbreak: an experience from Hong Kong. Eye (Lond). 2006;20:283-9.

11. WHO. Global Surveillance for human infection with novel coronavirus (2019-nCoV). World Health Organisation; 2020 https://www.who.int/publications-detail/global-surveillance-forhuman-infection-with-novel-coronavirus-(2019-ncov).

12. Casanova LM, Jeon S, Rutala WA, Weber DJ, Sobsey MD. Effects of air temperature and relative humidity on coronavirus survival on surfaces. Appl Environ Microbiol. 2010;76:2712-7.

13. Sizun J, Yu MW, Talbot PJ. Survival of human coronaviruses 229E and OC43 in suspension and after drying onsurfaces: a possible source ofhospital-acquired infections. J Hosp Infect. 2000;46:55-60. 